\title{
Synchrotron X-ray Diffraction Study of Structural Phase Transition in $\mathrm{Ca}_{10}\left(\mathrm{Ir}_{4} \mathrm{As}_{8}\right)\left(\mathrm{Fe}_{2-x} \mathrm{Ir}_{x} \mathrm{As}_{2}\right)_{5}$
}

\author{
Naoyuki Katayama $^{1 *}$, Kento Sugawara ${ }^{1}$, Yuki Sugiyama ${ }^{1}$, Takafumi Higuchi $^{1}$, \\ Kazutaka Kudo ${ }^{2}$, Daisuke Mitsuoka ${ }^{2}$, Takashi Mizokawa ${ }^{3}$, Minoru Nohara $^{2}$, and \\ Hiroshi Sawa ${ }^{1}$ \\ ${ }^{1}$ Department of Applied Physics, Nagoya University, Nagoya 464-8603, Japan \\ ${ }^{2}$ Department of Physics, Okayama University, Okayama 700-8530, Japan \\ ${ }^{3}$ Department of Physics and Department of Complex Science and Engineering, \\ University of Tokyo, Kashiwa, Chiba 27r7-8561, Japan
}

\begin{abstract}
We report on the structural phase transition found in $\mathrm{Ca}_{10}\left(\operatorname{Ir}_{4} \mathrm{As}_{8}\right)\left(\mathrm{Fe}_{2-x} \mathrm{Ir}_{x} \mathrm{As}_{2}\right)_{5}$, which exhibits superconductivity at $16 \mathrm{~K}$. The $c$-axis parameter is doubled below a structural transition temperature of approximately $100 \mathrm{~K}$, while the tetragonal symmetry with the space group $P 4 / n$ (No. 85) is unchanged at all temperatures measured. Our synchrotron X-ray diffraction study clearly shows iridium ions at a non-coplanar position shift along the $z$-direction at the structural phase transition. We discuss the fact that iridium displacements affect superconductivity in $\mathrm{Fe}_{2} \mathrm{As}_{2}$ layers.
\end{abstract}

Since the discovery of superconductivity in $\mathrm{LaFeAsO}_{1-x} \mathrm{~F}_{x},{ }^{1}$ the high- $T_{c}$ superconducting mechanism has been attributed to both the magnetic and structural properties of the material. All iron-based superconducting families identified so far consist of the same structural motif of $\mathrm{Fe}_{2} \mathrm{As}_{2}$ and spacer layers. ${ }^{2-19}$ Therefore, the crystal structure of a material can be classified according to the spacer layer. Examples include (i) 1111-type structures with slabs of rare-earth oxides or alkali-earth fluorides with a fluorite-type structure, ${ }^{1,2}$ (ii) 111- and 122-type structures with alkali or alkali-earth ions, ${ }^{3,4}$ (iii) a 32522-type structure and its derivative with complex metal oxides with a perovskitetype structure or combinations of perovskite- and rocksalt-type structures, ${ }^{5-12}$ (iv) a 112-type structure with arsenic zigzag chains, ${ }^{13,14}$ and (v) 10-4-8 and 10-3-8 phases as in $\mathrm{Ca}_{10}\left(\mathrm{Pt}_{n} \mathrm{As}_{8}\right)\left(\mathrm{Fe}_{2-x} \mathrm{Pt}_{x} \mathrm{As}_{2}\right)_{5}$ with $n=3$ and 4 and $\mathrm{Ca}_{10}\left(\operatorname{Ir}_{4} \mathrm{As}_{8}\right)\left(\mathrm{Fe}_{2-x} \operatorname{Ir}_{x} \mathrm{As}_{2}\right)_{5} \cdot{ }^{15-18}$ Generally, spacer layers are insulating in nature without any degrees of freedom. If there

*E-mail address: katayama@mcr.nuap.nagoya-u.ac.jp 
are degrees of freedom of spacer layers, such as charges, orbitals and lattices, we expect that their orderings or fluctuations will affect the superconductivity in $\mathrm{Fe}_{2} \mathrm{As}_{2}$ layers through intimate interlayer coupling, leading to a new controllable parameter.

To address the above mentioned issue, we present a structural study of $\mathrm{Ca}_{10}\left(\operatorname{Ir}_{4} \mathrm{As}_{8}\right)\left(\mathrm{Fe}_{2-x} \operatorname{Ir}_{x} \mathrm{As}_{2}\right)_{5}$ with a $T_{c}$ of $16 \mathrm{~K}$. This compound was first reported by Kudo et al. with the chemical formula $\mathrm{Ca}_{10}\left(\mathrm{Ir}_{4} \mathrm{As}_{8}\right)\left(\mathrm{Fe}_{2} \mathrm{As}_{2}\right)_{5}$ based on the synchrotron $\mathrm{X}$-ray diffraction analysis. ${ }^{15}$ In this study, we reanalyzed the chemical composition and found a small amount of Ir substitution for Fe, which will be discussed later. Both $\mathrm{Ca}_{10}\left(\operatorname{Ir}_{4} \mathrm{As}_{8}\right)\left(\mathrm{Fe}_{2-x} \mathrm{Ir}_{x} \mathrm{As}_{2}\right)_{5}$ and a platinum derivative, $\mathrm{Ca}_{10}\left(\mathrm{Pt}_{4} \mathrm{As}_{8}\right)\left(\mathrm{Fe}_{2-x} \mathrm{Pt}_{x} \mathrm{As}_{2}\right)_{5}$, reported by $\mathrm{Ni}$ et al., crystallize in tetragonal structures with the space group $P 4 / n{ }^{15,16}$ The most significant difference between them is related to their electron configurations: $\mathrm{Pt}^{2+}$ forms a closed-shell configuration with a completely filled $d_{x y}$ orbital owing to the $5 d^{8}$ electric state, whereas $\operatorname{Ir}^{2+}$ has a formally half-filled $5 d^{7}$ electric state. The two materials exhibit different temperature dependences in electrical conductivity, which is likely due to the different electron configurations of spacer layers. The resistivity of $\mathrm{Ca}_{10}\left(\mathrm{Pt}_{4} \mathrm{As}_{8}\right)\left(\mathrm{Fe}_{2-x} \mathrm{Pt}_{x} \mathrm{As}_{2}\right)_{5}$ decreases linearly with temperature, ${ }^{16}$ whereas that of $\mathrm{Ca}_{10}\left(\mathrm{Ir}_{4} \mathrm{As}_{8}\right)\left(\mathrm{Fe}_{2-x} \mathrm{Ir}_{x} \mathrm{As}_{2}\right)_{5}$ exhibits a kink near $100 \mathrm{~K}$, as shown in Fig. 1(a), suggesting that an unusual transition related to the electron configuration of the divalent iridium occurs. Kudo et al. suggested that the magnetic ordering is absent below $100 \mathrm{~K}$ based on the results of their Mössbauer experiment. ${ }^{15}$

In this letter, we present a synchrotron X-ray structural study of $\mathrm{Ca}_{10}\left(\mathrm{Ir}_{4} \mathrm{As}_{8}\right)\left(\mathrm{Fe}_{2-x} \mathrm{Ir}_{x} \mathrm{As}_{2}\right)_{5}$. Our analysis clearly shows the appearance of superstructure peaks below $100 \mathrm{~K}$, indicating a doubled period along the $c$-axis. In the low-temperature phase, half of the iridium ions shift along the $c$-axis, displacing the surrounding arsenic ions.

Single crystals of $\mathrm{Ca}_{10}\left(\operatorname{Ir}_{4} \mathrm{As}_{8}\right)\left(\mathrm{Fe}_{2-x} \mathrm{Ir}_{x} \mathrm{As}_{2}\right)_{5}$ were grown at Okayama University. The synthesis details have already been reported. ${ }^{15}$ The single-crystal X-ray diffraction experiments were performed at SPring-8 BL02B1 (Hyogo, Japan) using single crystals with typical dimensions of $40 \times 40 \times 70 \mu \mathrm{m}^{3}$. The X-ray wavelength was $0.52 \AA$. The obtained lattice parameters and refined conditions are summarized in Table I.

In our single-crystal X-ray diffraction experiments, superstructure peaks emerged near $100 \mathrm{~K}$, which nearly corresponded to the kink in the electric resistivity measurement, and the peaks increased in number as the sample was cooled, as shown in Fig. 1(b). The superstructure peaks indicate a doubled period along the $c$-axis direction be- 
Table I. Data collection and refinement statistics for the synchrotron X-ray structure determination of $\mathrm{Ca}_{10}\left(\mathrm{Ir}_{4} \mathrm{As}_{8}\right)\left(\mathrm{Fe}_{2-x} \operatorname{Ir}_{x} \mathrm{As}_{2}\right)_{5}$.

\begin{tabular}{lcl}
\hline \hline $\mathrm{Ca}_{10}\left(\mathrm{Ir}_{4} \mathrm{As}_{8}\right)\left(\mathrm{Fe}_{2-x} \mathrm{Ir}_{x} \mathrm{As}_{2}\right)_{5}$ & \multicolumn{1}{c}{$293 \mathrm{~K}$} & $20 \mathrm{~K}$ \\
\hline \hline & Data Collection & \\
Crystal System & tetragonal & tetragonal \\
Space Group & $P 4 / n$ & $P 4 / n$ \\
$a(\AA)$ & $8.73230(10)$ & $8.7236(17)$ \\
$c(\AA)$ & $10.391(4)$ & $20.6799(18)$ \\
$R$ merge & 0.0613 & 0.0614 \\
$I / \sigma I$ & $>2$ & $>2$ \\
& & \\
\hline \multicolumn{2}{c}{ Refinement } & $>0.50$ \\
Resolution $(\AA)$ & $>0.50$ & 3457 \\
No. of Unique Reflections & 2329 & 0.0409 \\
$R 1$ & 0.0369 & \\
\hline \hline
\end{tabular}

Table II. Structural parameters collected at $293 \mathrm{~K} . M(3)$ and $M(4)$ represent $\mathrm{Fe}_{1-x / 2} \operatorname{Ir}_{x / 2}$ with $x$ $=0.085(3)$ and $0.059(2)$, respectively. The occupancy is fixed at 1 in all atomic sites.

\begin{tabular}{lccc}
\hline \hline \multicolumn{4}{c}{$\mathrm{Ca}_{10}\left(\mathrm{Ir}_{4} \mathrm{As}_{8}\right)\left(M_{2} \mathrm{As}_{2}\right)_{5}$ at $293 \mathrm{~K}}$. \\
Atomic Position \\
Site & $x / a$ & $y / b$ & $z / c$ \\
\hline $\mathrm{Ir}(1)$ & $3 / 4$ & $1 / 4$ & $-1 / 2$ \\
$\mathrm{Ir}(2)$ & $3 / 4$ & $3 / 4$ & $-0.56465(4)$ \\
$M(3)$ & $3 / 4$ & $1 / 4$ & 0 \\
$M(4)$ & $0.05219(5)$ & $0.34938(6)$ & $-0.00473(5)$ \\
$\mathrm{As}(5)$ & $0.64044(4)$ & $0.50455(5)$ & $-0.49958(4)$ \\
$\mathrm{As}(6)$ & $1 / 4$ & $1 / 4$ & $-0.14574(9)$ \\
$\mathrm{As}(7)$ & $0.84898(4)$ & $0.45365(4)$ & $-0.13567(4)$ \\
$\mathrm{Ca}(8)$ & $0.55128(8)$ & $0.34551(9)$ & $-0.26082(8)$ \\
$\mathrm{Ca}(9)$ & $3 / 4$ & $3 / 4$ & $-0.27298(17)$ \\
\hline \hline
\end{tabular}

low the transition. As shown in Fig. 1(c), the lattice parameters show no discontinuous jump at $100 \mathrm{~K}$, suggesting that the transition is of the second order.

Through careful investigation of the Laue symmetry and the extinction rule of $h+k \neq 2 n$ for $h k 0$, we found that the structural symmetry at $20 \mathrm{~K}$ was tetragonal with the space group $P 4 / n$, indicating that the space group was unchanged across 


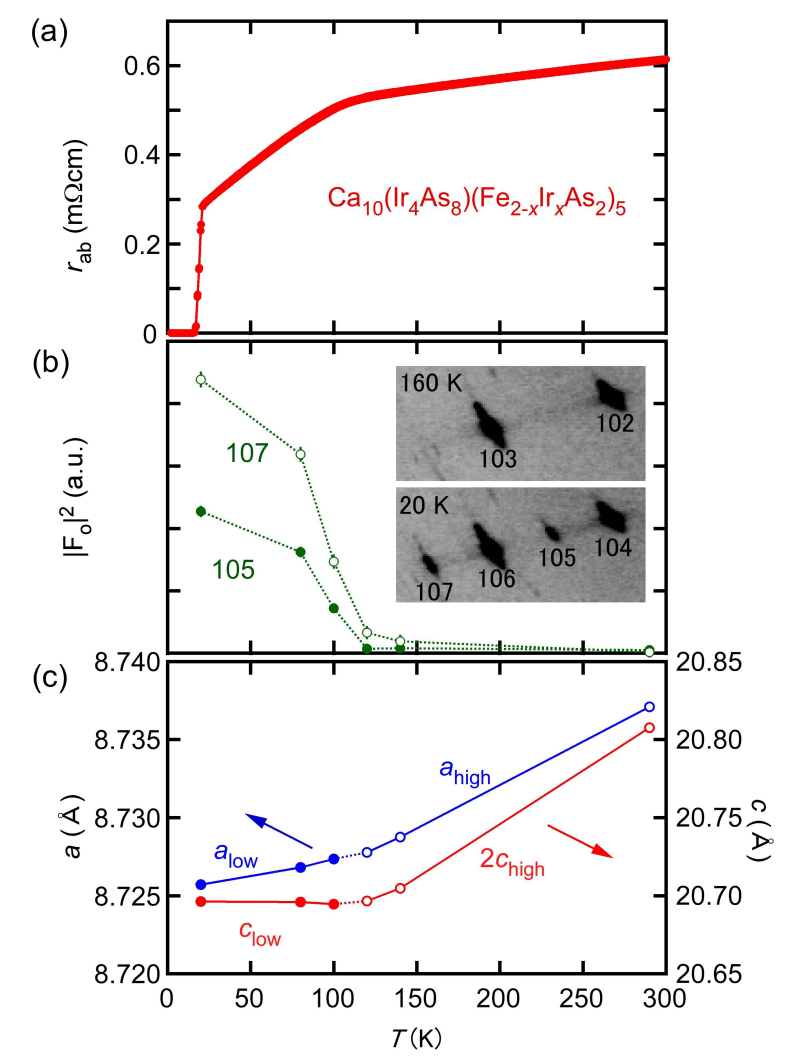

Fig. 1. (Color online) (a) Temperature dependence of the electrical resistivity parallel to the $a b$ plane, $\rho_{\mathrm{ab}}$, for $\mathrm{Ca}_{10}\left(\mathrm{Ir}_{4} \mathrm{As}_{8}\right)\left(\mathrm{Fe}_{2-x} \mathrm{Ir}_{x} \mathrm{As}_{2}\right)_{5}$, which has been reported in Ref 15 . Note that a small kink appears near $100 \mathrm{~K}$. (b) Temperature dependence of the square of the observed structure factor, $\left|F_{o}\right|^{2}$, which is proportional to the superstructure peak intensity. (c) Lattice parameters at each temperature, where $c_{\text {low }}$ and $c_{\text {high }}$ indicate the $c$-axis parameters in the low-temperature and high-temperature phases, respectively.

the transition. Our precise definition of the composition showed a small amount of Ir substituted for Fe in the present samples, which was not reported in a previous study. ${ }^{15}$ The high-temperature and low-temperature structural data are summarized in Tables II and III, respectively. Crystal information files (CIFs) of the crystal structure of $\mathrm{Ca}_{10}\left(\mathrm{Ir}_{4} \mathrm{As}_{8}\right)\left(\mathrm{Fe}_{2-x} \mathrm{Ir}_{x} \mathrm{As}_{2}\right)_{5}$ at 293 and $20 \mathrm{~K}$ derived by analysis can be obtained free of charge from The Cambridge Crystallographic Data Centre via www.ccdc.cam.ac.uk. CCDC 1016394 and 1016395 contain the crystallographic data for this paper.

The space group $P 4 / n$ is preserved at the lowest measured temperatures, although some atomic sites become two distinct sites, as shown in Figs. 2(a) and 2(b). The most notable structural features appear near the iridium ions. There are two iridium sites at high temperatures: $\operatorname{Ir}(1)$ is at a coplanar site and $\operatorname{Ir}(2)$, which becomes two distinct 
Table III. Structural parameters collected at $20 \mathrm{~K}$. Below the transition, all atomic sites, except for $\operatorname{Ir}(1)$, become two distinct sites. $M(3 \mathrm{a}), M(3 \mathrm{~b}), M(4 \mathrm{a})$, and $M(4 \mathrm{~b})$ represent $\mathrm{Fe}_{1-x / 2} \mathrm{Ir}_{x / 2}$ with $x$ $=0.089(3)$ for $M(3 \mathrm{a})$ and $M(3 \mathrm{~b})$, and $x=0.062(2)$ for $M(4 \mathrm{a})$ and $M(4 \mathrm{~b})$. Here, $M(3 \mathrm{a})$ and $M(3 \mathrm{~b})$ are derived from $M(3)$, while $M(4 \mathrm{a})$ and $M(4 \mathrm{~b})$ are derived from $M(4)$. The occupancy is fixed at 1 in all atomic sites.

\begin{tabular}{lccc}
\hline \hline \multicolumn{4}{c}{$\mathrm{Ca}_{10}\left(\mathrm{Ir}_{4} \mathrm{As}_{8}\right)\left(M_{2} \mathrm{As}_{2}\right)_{5}$ at $20 \mathrm{~K}}$. \\
\hline \multicolumn{4}{c}{ Atomic Position } \\
Site & $x / a$ & $y / b$ & $z / c$ \\
\hline $\mathrm{Ir}(1)$ & $1 / 4$ & $-1 / 4$ & $0.247974(14)$ \\
$\mathrm{Ir}(2 \mathrm{a})$ & $-1 / 4$ & $-1 / 4$ & $0.20958(2)$ \\
$\mathrm{Ir}(2 \mathrm{~b})$ & $1 / 4$ & $1 / 4$ & $0.27449(2)$ \\
$M(3 \mathrm{a})$ & $-3 / 4$ & $-1 / 4$ & 0 \\
$M(3 \mathrm{~b})$ & $1 / 4$ & $-1 / 4$ & $1 / 2$ \\
$M(4 \mathrm{a})$ & $-0.34874(9)$ & $-0.44598(9)$ & $0.00378(4)$ \\
$M(4 \mathrm{~b})$ & $-0.05035(9)$ & $-0.35010(9)$ & $0.50078(4)$ \\
$\mathrm{As}(5 \mathrm{a})$ & $-0.14200(8)$ & $-0.00692(8)$ & $0.25072(3)$ \\
$\mathrm{As}(5 \mathrm{~b})$ & $0.13935(8)$ & $0.00283(8)$ & $0.24954(3)$ \\
$\mathrm{As}(6 \mathrm{a})$ & $-1 / 4$ & $-1 / 4$ & $0.07647(6)$ \\
$\mathrm{As}(6 \mathrm{~b})$ & $-1 / 4$ & $-1 / 4$ & $0.56830(6)$ \\
$\mathrm{As}(7 \mathrm{a})$ & $-0.54546(8)$ & $-0.34881(8)$ & $-0.06679(3)$ \\
$\mathrm{As}(7 \mathrm{~b})$ & $0.04737(7)$ & $-0.15073(7)$ & $0.43176(3)$ \\
$\mathrm{Ca}(8 \mathrm{a})$ & $0.05329(14)$ & $-0.15489(14)$ & $0.12963(6)$ \\
$\mathrm{Ca}(8 \mathrm{~b})$ & $-0.04915(14)$ & $0.15412(15)$ & $0.36948(6)$ \\
$\mathrm{Ca}(9 \mathrm{a})$ & $1 / 4$ & $1 / 4$ & $0.13355(11)$ \\
$\mathrm{Ca}(9 \mathrm{~b})$ & $-1 / 4$ & $-1 / 4$ & $0.36103(12)$ \\
\hline \hline
\end{tabular}

sites of $\operatorname{Ir}(2 \mathrm{a})$ and $\operatorname{Ir}(2 \mathrm{~b})$ at low temperatures, is at a non-coplanar site with respect to the As square. At the transition, $\operatorname{Ir}(2 b)$ shifts toward the center of the As square, as shown in Figs. 2(c) and 2(e). In contrast, $\operatorname{Ir}(2 \mathrm{a})$ is displaced toward the As(6a) ion in the adjacent $\mathrm{Fe}_{2} \mathrm{As}_{2}$ layer, resulting in an almost $10 \%$ reduction in the $\operatorname{Ir}(2 \mathrm{a})-\mathrm{As}(6 \mathrm{a})$ distance compared with that at $293 \mathrm{~K}$, as shown in Figs. 2(c) and 2(d). Note that As(6a) also shifts toward $\operatorname{Ir}(2 \mathrm{a})$ at low temperatures, suggesting a strong tendency toward the bonding between $\operatorname{Ir}(2 \mathrm{a})$ and $\operatorname{As}(6 \mathrm{a})$.

What is the origin of the unusual structural transition found using the synchrotron X-ray diffraction experiment? One of the possible scenarios relates to the band splitting of arsenic, which is analogous to the structural transition found in $\mathrm{IrTe}_{2}$ with a twodimensional triangular lattice. ${ }^{20} \mathrm{IrTe}_{2}$ shows the structural transition caused by the 


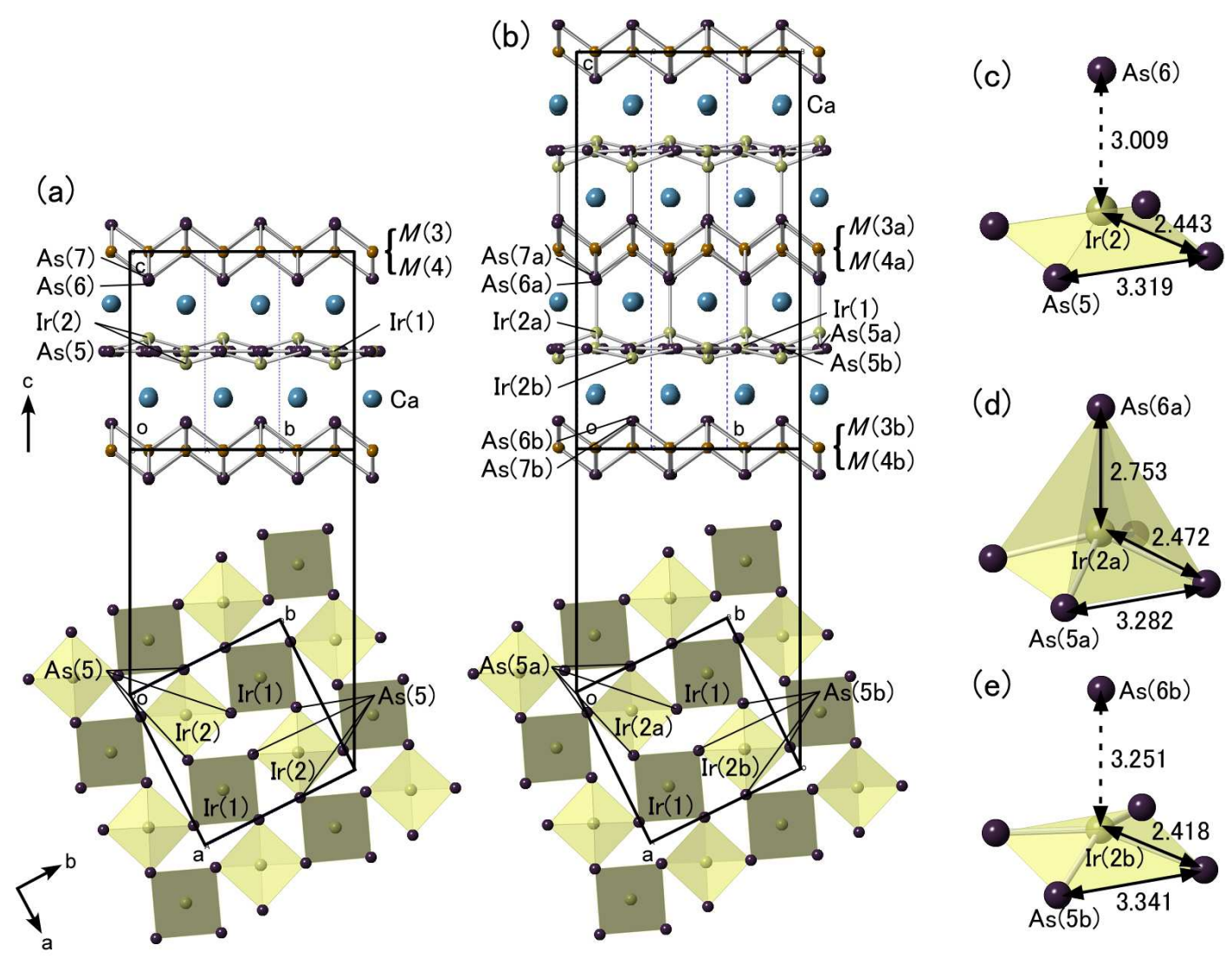

Fig. 2. (Color online) Crystal structures of $\mathrm{Ca}_{10}\left(\mathrm{Ir}_{4} \mathrm{As}_{8}\right)\left(\mathrm{Fe}_{2-x} \mathrm{Ir}_{x} \mathrm{As}_{2}\right)_{5}$ at (a) 293 and (b) $20 \mathrm{~K}$. Atomic distances between the iridium and arsenic ligands, where (c) represents $\operatorname{Ir}(2)$ and the ligands at $293 \mathrm{~K}$, while (d) and (e) show $\operatorname{Ir}(2 \mathrm{a})$ and $\operatorname{Ir}(2 \mathrm{~b})$ with the arsenic ligands at $20 \mathrm{~K}$, respectively.

crystal field effect, which further splits the energy levels of Te $\left(p_{x}, p_{y}\right)$ and Te $p_{z}$. Such a tellurium-originated structural transition is absent in the platinum analogue $\mathrm{PtTe}_{2}$, which also seems to be similar to the present systems. This scenario, however, seems not to be the case in the present systems because the displacements of $\operatorname{Ir}(2 \mathrm{a})$ and $\operatorname{Ir}(2 \mathrm{~b})$ at the transition are much larger than those of the surrounding arsenic ions, which is sharply different from the structural transition in $\mathrm{IrTe}_{2}$ with large displacements of tellurium. The experimentally observed large displacements of iridium ions make us expect the modification of bonding characters between iridium and surrounding arsenic ions.

Experimentally observed strong tendency toward bonding formation between $\operatorname{Ir}(2 \mathrm{a})$ and $\operatorname{As}(6 a)$ makes us expect that an unpaired electron occupies the $\operatorname{Ir}(2 \mathrm{a}) 5 d_{3 z^{2}-r^{2}}$ orbital, which spreads toward $\mathrm{As}(6 \mathrm{a})$ directions and contributes to the bonding between $\operatorname{Ir}(2 \mathrm{a})$ and $\operatorname{As}(6 \mathrm{a})$. Note that the divalent nature of iridium ions has already been 
confirmed by X-ray photoelectron spectroscopy (XPS) ${ }^{15}$ indicating the formal electron counts of $5 d^{7}$. To determine whether the unpaired electron indeed occupies $5 d_{3 z^{2}-r^{2}}$ orbital, we performed the configuration interaction calculation on the $\operatorname{IrAs}_{5}$ cluster model with $d^{7}, d^{8} L$, and $d^{9} L^{2}$ configurations, where $L$ represents a ligand hole.

In the cluster model calculation, the ground and excited states are given by linear combinations of $d^{7}, d^{8} L$, and $d^{9} L^{2}$ configurations, where $L$ denotes a hole in the As $4 p$ orbitals. The charge-transfer energy $\Delta$ corresponds to $E\left(d^{8} L\right)-E\left(d^{7}\right)$. Here, $E\left(d^{n} L^{m}\right)$ represents the average energy of the $d^{n} L^{m}$ states. $E\left(d^{9} L^{2}\right)-E\left(d^{8} L^{2}\right)$ is given by $\Delta+$ $U$, where $U$ is the multiplet average Coulomb interaction between the $d$ electrons. The Ir $5 d$ spin-orbit interaction $\zeta_{d}$ is set to $0.5 \mathrm{eV}$. The Racah parameters $B$ and $C$ for the Ir $5 d$ orbitals are set to zero since the Hund exchange energy $(5 B / 2+C)$ is negligible in Ir $5 d$ compounds compared with $U$. The hybridization terms between $d^{7}$ and $d^{8} L$ (or $d^{8} L$ and $\left.d^{9} L^{2}\right)$ are given by $(p d \sigma)$ and $(p d \pi)$, where $(p d \sigma) /(p d \pi)=-2.16$. $\Delta, U$, and $(p d \sigma)$ are set to $2.0,1.0$, and $-1.5 \mathrm{eV}$, respectively, considering the results of band calculations, ${ }^{15}$ photoemission experiments, and chemical trends of the parameters. The present conclusion does not change if the three parameters are changed within a reasonable range. For example, the calculated results are essentially the same when $(p d \sigma)$ is increased to $-2.0 \mathrm{eV}$ or decreased to $-1.0 \mathrm{eV}$. Figure 3 shows the energies of the ground and excited states as a function of the $\operatorname{Ir}(2)-\operatorname{As}(5)-\operatorname{As}(6)$ bond angle $\theta$. The $\operatorname{Ir}(2 \mathrm{~b})$ site can be regarded as a square planar coordination since the apical As(6b) is far from the basal plane. As expected, the unpaired electron occupies $5 d_{3 z^{2}-r^{2}}$ in the ground state. However, the energy splitting between $5 d_{3 z^{2}-r^{2}}$ and $5 d_{x y}$ is as small as $\sim 0.2 \mathrm{eV}$, which is comparable to or smaller than the hybridization energy between neighboring clusters. Therefore, in the $\operatorname{Ir}(2 \mathrm{~b})$ site, the unpaired electron can be a mixture of $5 d_{3 z^{2}-r^{2}}$ and $5 d_{x y}$. On the other hand, in the $\operatorname{Ir}(2 \mathrm{a})$ site, the apical $\mathrm{As}(6 \mathrm{a})$ approaches to the basal plane and, consequently, the unpaired electron tends to be pure $5 d_{3 z^{2}-r^{2}}$ with a larger energy splitting. Therefore, the present cluster model calculation suggests that the structural distortion discovered in the present work is accompanied by the Ir $5 d$ orbital change. If the apical $\mathrm{As}(6 \mathrm{a})$ is much closer to the basal plane $\left(\theta<42^{\circ}\right)$, the unpaired electron is predicted to occupy $5 d_{x^{2}-y^{2}}$ in the ground state. Here, it should be noted that the impact of the Ir $5 d$ spin-orbit interaction on the $\operatorname{Ir} 5 d_{x y} / 5 d_{y z}$ orbitals is much stronger than those on the Ir $5 d_{3 z^{2}-r^{2}}, 5 d_{x^{2}-y^{2}}$, and $5 d_{x y}$ orbitals.

Although the displacement of $\operatorname{Ir}(2 \mathrm{a})$ toward the $\mathrm{As}(6 \mathrm{a})$ direction causes the contraction of the As(5a) square, as shown in Figs. 2(c) and 2(d), the As(5b) square 
expands below the transition temperature, accompanied by the displacement of $\operatorname{Ir}(2 \mathrm{~b})$ toward the center of the As square, as shown in Figs. 2(c) and 2(e), resulting in the appearance of the breathing square lattice in the $\operatorname{Ir}_{4} \mathrm{As}_{8}$ layer. Note that similar breathing lattices can also be found in other systems. The spinel oxides, $\mathrm{LiGaCr}_{4} \mathrm{O}_{8}$ and LiInCr ${ }_{4} \mathrm{O}_{8},{ }^{21}$ consist of an inherently distorted breathing pyrochlore lattice owing to the large size mismatch between $\mathrm{Li}^{+}$and $\mathrm{Ga}^{3+} / \mathrm{In}^{3+}$ ions at the $A$ site. The perovskite oxides $\mathrm{CaFeO}_{3},{ }^{22} \mathrm{YNiO}_{3},{ }^{23}$ and $\mathrm{NdNiO}_{3},{ }^{24,25}$ belong to another system with a breathing lattice. The breathing distortion is realized in relation to the charge disproportionation of $B$ site transition metals. In the present system, any degrees of freedom of iridium should be related to the emergence of a breathing lattice, as presented above. Furthermore, the intimate coupling between $\mathrm{Ir}_{4} \mathrm{As}_{8}$ and the adjusting $\mathrm{Fe}_{2} \mathrm{As}_{2}$ layers also holds the key for realizing a breathing lattice. If both $\operatorname{Ir}(2 \mathrm{a})$ and $\operatorname{Ir}(2 \mathrm{~b})$ displace toward the same direction with regard to the As squares, both As(1a) and As(1b) squares should expand or contract together in relation with the displacement of iridium, leading to the destruction of the commensurate periodicity between $\mathrm{Fe}_{2} \mathrm{As}_{2}$ and $\mathrm{Ir}_{4} \mathrm{As}_{8}$ layers by an abrupt change in the size of the $\operatorname{Ir}_{4} \mathrm{As} s_{8}$ planes across the transition. In the present system, the commensurate periodicity is preserved between $\mathrm{Fe}_{2} \mathrm{As}_{2}$ and $\mathrm{Ir}_{4} \mathrm{As}_{8}$ layers without any discontinuous jumps in the $a$-axis parameter, which softens the change in the size of the $\operatorname{Ir}_{4} \mathrm{As}_{8}$ planes across the transition.

Finally, we discuss superconductivity at low temperatures. The present structural transition should affect superconductivity in $\mathrm{Fe}_{2} \mathrm{As}_{2}$ layers through intimate interlayer couplings. Associated with the iridium displacements, $\mathrm{Fe}_{2} \mathrm{As}_{2}$ layers become two crystallographically inequivalent $\mathrm{Fe}_{2} \mathrm{As}_{2}$ layers below the transition, as shown in Fig. 2(b): one layer includes $\mathrm{As}(6 \mathrm{a})$, which is strongly coupled with $\operatorname{Ir}_{4} \mathrm{As}_{8}$ layers through $\operatorname{Ir}(2 \mathrm{a})$ As(6a) bondings, while the other layer contains As(6b), which is apart from the adjacent $\mathrm{Ir}_{4} \mathrm{As}_{8}$ layers. Therefore, the displacement of arsenic ions associated with iridium displacements introduces notable differences in the As-Fe-As bond angles between the two $\mathrm{Fe}_{2} \mathrm{As}_{2}$ layers; the angle ranges from 105.58(4) to $112.29(4)^{\circ}$ for the layers containing $\mathrm{As}(6 \mathrm{a})$ and from 107.14(4) to $110.69(4)^{\circ}$ for the layers containing $\mathrm{As}(6 \mathrm{~b})$, which can be compared with the angle $\left(109.47^{\circ}\right)$ of a regular tetrahedron. This indicates that any degrees of freedom of iridium composed of spacer layers can cause the divergence in the crystal field between two distinct $\mathrm{Fe}_{2} \mathrm{As}_{2}$ layers and the resulting rearrangement of energy bands around the Fermi level, which should significantly affect superconductivity.

Unlike $\quad \mathrm{Ca}_{10}\left(\mathrm{Ir}_{4} \mathrm{As}_{8}\right)\left(\mathrm{Fe}_{2-x} \mathrm{Ir}_{x} \mathrm{As}_{2}\right)_{5}$, the platinum derivative 
$\mathrm{Ca}_{10}\left(\mathrm{Pt}_{4} \mathrm{As}_{8}\right)\left(\mathrm{Fe}_{2-x} \mathrm{Pt}_{x} \mathrm{As}_{2}\right)_{5}$ with space group $P 4 / n$ exhibits no structural transitions. Because $\mathrm{Ca}_{10}\left(\mathrm{Pt}_{4} \mathrm{As}_{8}\right)\left(\mathrm{Fe}_{2-x} \mathrm{Pt}_{x} \mathrm{As}_{2}\right)_{5}$ shows superconductivity with a higher transition temperature of $25 \mathrm{~K},{ }^{15,16}$ we can naively speculate that the structural transition suppresses superconductivity in the present system. However, we would like to point out that the second order structural transition in the present system may bring us further opportunities to study the relationship between superconductivity and structural instability, by suppressing the structural transition using any methods such as chemical doping or the application of pressure.

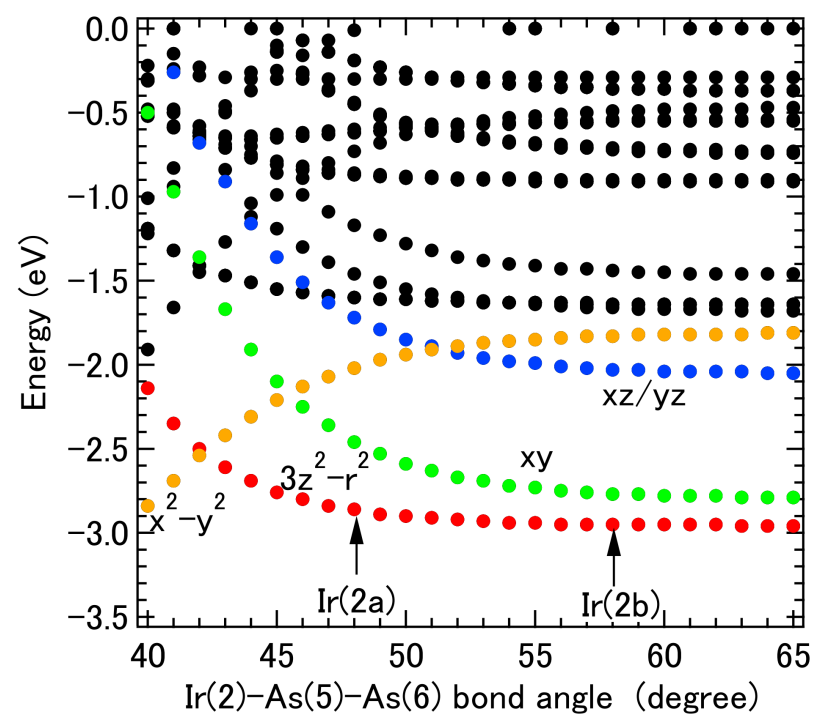

Fig. 3. (Color online) Energies of ground and excited states as a function of $\operatorname{Ir}(2)-\operatorname{As}(5)-\operatorname{As}(6)$ bond angles obtained from the $\mathrm{IrAs}_{5}$ cluster model calculation.

In summary, we studied the nature of the structural transition found in $\mathrm{Ca}_{10}\left(\mathrm{Ir}_{4} \mathrm{As}_{8}\right)\left(\mathrm{Fe}_{2-x} \operatorname{Ir}_{x} \mathrm{As}_{2}\right)_{5}$, which undergoes a superconducting transition at $16 \mathrm{~K}$, using synchrotron X-ray diffraction experiments. Our X-ray diffraction analysis results reveal the displacement of iridium and the associated arsenic displacement below the transition temperature. Combining these results with $\operatorname{IrAs}_{5}$ cluster calculations, we conclude that all degrees of freedom of divalent iridium play an important role in structural transition.

\section{Acknowledgements}

The work at Nagoya University was supported by a Grant-in-Aid for Scientific Research (No. 23244074), Kumagai Foundation for Science and Technology, Toukai Foun- 
dation for Technology, and Nippon Sheet Glass Foundation for Materials Science and Engineering. The work at Okayama University was partially supported by a Grant-inAid for Scientific Research (C) (No. 25400372) from the Japan Society for the Promotion of Science (JSPS) and the Funding Program for World-Leading Innovative R\&D on Science and Technology (FIRST Program) from JSPS. Some of the magnetization measurements were performed at the Advanced Science Research Center at Okayama University. The synchrotron radiation experiments performed at BL02B1 in SPring-8 were supported by the Japan Synchrotron Radiation Research Institute (JASRI) (Proposal Nos. 2012A0083, 2012B0083, 2013A0083, and 2013B0083). 


\section{References}

1) Y. Kamihara, T. Watanabe, M. Hirano, and H. Hosono, J. Am. Chem. Soc. 130, 3296 (2008).

2) S. Matsuishi, Y. Inoue, T. Nomura, H. Yanagi, M. Hirano, and H. Hosono, J. Am. Chem. Soc. 130, 14428 (2008).

3) J. H. Tapp, Z. Tang, B. Lv, K. Sasmal, B. Lorenz, P. C. W. Chu, and A. M. Guloy, Phys. Rev. B 78, 060505(R) (2008).

4) M. Rotter, M. Tegel, and D. Johrendt, Phys. Rev. Lett. 101, 107006 (2008).

5) N. Kawaguchi, H. Ogino, Y. Shimizu, K. Kishio, and J. Shimoyama, Appl. Phys. Express 3, 063102 (2010).

6) X. Zhu, F. Han, G. Mu, P. Cheng, B. Shen, B. Zeng, and H.-H. Wen, Phys. Rev. B 79, 220512(R) (2009).

7) H. Ogino, K. Machida, A. Yamamoto, K. Kishio, J. Shimoyama, T. Tohei, and Y. Ikuhara, Supercond. Sci. Technol. 23, 115005 (2010).

8) P. M. Shirage, K. Kihou, C.-H. Lee, H. Kito, H. Eisaki, and A. Iyo, Appl. Phys. Lett. 97, 172506 (2010).

9) H. Ogino, Y. Katsura, S. Horii, K. Kishio, and J. Shimoyama, Supercond. Sci. Technol. 22, 085001 (2009).

10) Y. Matsumura, H. Ogino, S. Horii, Y. Katsura, K. Kishio, and J. Shimoyama, Appl. Phys. Express 2, 063007 (2009).

11) S. Sato, H. Ogino, N. Kawaguchi, Y. Katsura, K. Kishio, J. Shimoyama, H. Kotegawa, and H. Tou, Supercond. Sci. Technol. 23, 045001 (2010).

12) H. Ogino, S. Sato, K. Kishio, J. Shimoyama, T. Tohei, and Y. Ikuhara, Appl. Phys. Lett. 97, 072506 (2010).

13) N. Katayama, K. Kudo, S. Onari, T. Mizukami, K. Sugawara, Y. Sugiyama, Y. Kitahama, K. Iba, K. Fujimura, N. Nishimoto, M. Nohara, and H. Sawa, J. Phys. Soc. Jpn. 82, 123702 (2013).

14) H. Yakita, H. Ogino, T. Okada, A. Yamamoto, K. Kishio, T. Tohei, Y. Ikuhara, Y. Gotoh, H. Fujihisa, K. Kataoka, H. Eisaki, and J. Shimoyama, J. Am. Chem. Soc. 136, 846 (2014). 
15) K. Kudo, D. Mitsuoka, M. Takasuga, Y. Sugiyama, K. Sugawara, N. Katayama, H. Sawa, H. S. Kubo, K. Takamori, M. Ichioka, T. Fujii, T. Mizokawa, and M. Nohara, Sci. Rep. 3, 3101 (2013).

16) N. Ni, J. M. Allred, B. C. Chan, and R. J. Cava, Proc. Natl. Acad. Sci. U.S.A. 108, E1019 (2011).

17) C. Hieke, J. Lippmann, T. Stürzer, G. Friederichs, F. Nitsche, F. Winter, R. Pöttgen, and D. Johrendt, Philos. Mag. 93, 3680 (2013).

18) S. Kakiya, K. Kudo, Y. Nishikubo, K. Oku, E. Nishibori, H. Sawa, T. Yamamoto, T. Nozaka, and M. Nohara, J. Phys. Soc. Jpn. 80, 093704 (2011).

19) Z. A. Ren, W. Lu, J. Yang, W. Yi, X. L. Shen, Z. C. Li, G. C. Che, X. L. Dong, L. L. Sun, F. Zhou, and Z. X. Zhao, Chin. Phys. Lett. 25, 2215 (2008).

20) A. F. Fang, G. Xu, T. Dong, P. Zheng, and N. L. Wang, Sci. Rep. 3, 1153 (2012).

21) Y. Okamoto, G. J. Nilsen, J. P. Attfield, and Z. Hiroi, Phys. Rev. Lett. 110, 097203 (2013).

22) J. A. Alonso, J. L. García-Munõz, M. T. Fernández-Díaz, M. A. G. Aranda, M. J. Martínez-Lope, and M. T. Casais, Phys. Rev. Lett. 82, 3871 (1999).

23) M. Zaghrioui, A. Bulou, P. Lacorre, and P. Laffez, Phys. Rev. B 64, 081102(R) (2001).

24) P. M. Woodward, D. E. Cox, E. Moshopoulou, A. W. Sleight, and S. Morimoto, Phys. Rev. B 62, 844 (2000).

25) T. Takeda, R. Kanno, Y. Kawamoto, M. Takano, S. Kawasaki, T. Kamiyama, and F. Izumi, Solid State Sci. 2, 673 (2000). 